\title{
The privilege of public service and the dangers of populist technocracy: a response to Michael Gove and Dominic Cumming's 2020 Ditchley annual lecture
}

\author{
David Blunkett $^{1,2} \cdot$ Matthew Flinders $^{1}$
}

Published online: 18 October 2020

(c) Springer Nature Limited 2020

\begin{abstract}
On 27 June 2020, the Chancellor of the Duchy of Lancaster and Minister for the Cabinet Office, Michael Gove, gave the Ditchley Annual Lecture on the theme of 'the privilege of public service'. Although the fact that it took place in the context of the broader Coronavirus crisis meant that it received relatively little publicity or attention, the central argument of this article is that the lecture provides great insight into the ideas shaping government policy, in general, and into the inner mind of Dominic Cummings, in particular. As such, we argue that although the lecture was given by Michael Gove, it was clearly floating ideas and themes that were taken, almost directly, from Dominic Cummings' website. We draw out and explore these themes and suggest that what they combine to offer is a dangerous blend of technocratic populism that is as intellectually splintered as it is politically naïve.
\end{abstract}

Keywords Populism · Technocracy · Governance · Cummings · Whitehall · Expertise

\section{Introduction}

The Ditchley Annual Lecture dates back over fifty years and is used to focus attention on a specific pressing theme, to build a network of interested people and to draw new talent into future debates and discussions. To review the list of previous lecturers and topics is to look upon an incredibly distinguished list of speakers exploring some of the most profound issues facing humanity. 'The Dimensions of the

Matthew Flinders

m.flinders@sheffield.ac.uk

David Blunkett

brightside@parliament.uk

1 University of Sheffield, Sheffield, UK

2 The House of Lords, London, UK 
Atlantic Alliance' (General Lauris Norstad, 1963), 'The English Speaking People in a Changing World' (Sir Robert Menzies, 1967), 'The Americans and Europe' (The Hon. McGeorge Bundy, 1969), 'On the Usefulness of Biological Science' (Dr Lewis Thomas, 1980), 'Philosophy and Public Policy' (Dame Mary Warnock, 1984), 'The French Revolution and the Development of Western Democracy' (Mr François Furet, 1989), 'The Next Half-Century: A Scientist's Hopes and Fears' (Lord Rees, 2008) ... the list goes on, but one of the most obvious and striking elements about the 2020 Ditchley Lecture is that it makes no mention of those that have gone before it (https://www.ditchley.com/programme/annual-lecture). The fact that this common courtesy is not respected at all is made all the more striking by the simple fact that many of the previous lectures dealt very directly with this year's topic (i.e. democracy, the state and technological and scientific change). This is not, if we are honest, a lecture on 'the privilege of public service' but on the need for transformative change in Whitehall, and yet John Major's 2011 lecture on the same topic-'The Changing Face of Government' - is not given the privilege of even being mentioned as in any way relevant.

This failure to follow traditional conventional courtesy is, we suggest, symptomatic of a deeper strain of thinking that imbues this lecture and which urgently needs to be foregrounded as part of a broader debate about the future of democracy, civil service reform and the role of technology at the intersection between the governors and the governed. Indeed, what makes the 2020 Ditchley Lecture particularly significant is that, despite its best efforts, it does not stand alone and is in fact a key element of a broader process through which core members of the current government are seeking to develop, refine and most of all test out their ideas about the nature and scope of the reform agenda they feel is necessary. Let us be very clear from the outset: although Michael Gove may have stood at the lectern (or possibly in the context of Covid been digitally channelled to his distributed audience at the agreed time) this was not his lecture; the lecture has a schizophrenic quality, as we will illustrate, in the sense that some sections possess a clear and calm quality whereas others adopt a rather frenzied and deeply disruptive quality. It's as if Michael Gove stood on stage while 'a wild man in the wings' ranted and raved and demanded to be heard. This notion of a 'wild man in the wings' is, as many readers will have recognised, taken from Noam Chomsky's 1967 essay on 'The Responsibility of Intellectuals' which highlights the role of intellectuals to 'expose the lies of governments, to analyse actions according to their causes and motives and often hidden intentions' (Chomsky 1967).

More relevant to those interested in understanding the broader significance of the 2020 Ditchley Lecture is the way in which Chomsky used his article to distinguish between two types of intellectual. The first was the technocratic and policyorientated intellectual that focused their energies on refining and tinkering with the actually existing system and could therefore be trusted as 'responsible men'. These were the academic experts that fell into place, passively adopting the conventions instituted by the structures of authority carrying out 'faithfully the instructions of those who hold the reins of power, to be loyal and faithful servants, not after reflective judgement but by reflexive conformism'. The second group were the valueorientated intellectuals who were concerned with the realm of ideas, challenging 
dominant ideological frameworks and who placed contemporary issues in a historical context. These were the 'wild men in the wings' that were often dismissed or denigrated by those in power as over-emotional, destructive and lacking in loyalty. Chomsky's concern was that a form of species depletion had occurred whereby technocratic and policy-orientated intellectuals had become dominant, while value-orientated intellectuals had become almost extinct. Although an undoubtedly slightly odd connection to make, it is possible to forge a link between Chomsky's dichotomy and the 2020 Ditchley Lecture due to the manner in which the latter offers a rather hybridised intellectual vision; that is, a profoundly value-orientated technocratic and policy-orientated model of statecraft which is as potentially politically profound as it is clearly intellectually fractured.

This is a critical point. It has become increasingly clear, not least in recent months and concerning Covid, that Dominic Cummings enjoys a highly privileged, hugely powerful and closely protected position at the centre of British government. He is as idiosyncratic as he is unpredictable; he relishes in defying convention and refuses to play by the rules; he believes in the merits of creative disruption and is clearly a disruptive character. And yet, as Stefan Collini found, getting 'inside the mind of Dominic Cummings' is far from easy, which is why the 2020 Ditchley Lecture arguably provides such insight and deserves such discussion (Collini 2020). Michael Gove and Dominic Cummings worked together on the education policy brief from 2007 to 2013 and have since then been politically, professionally and intellectually united in their loathing of 'the blob' (i.e. the ability of bureaucratic structures and vested interests to block reform or what Cummings has termed 'wading through concrete'). Both are Oxford-educated humanities graduates (Gove graduating with an UpperSecond in English, Cummings with a First in Ancient and Modern History) who appear to have been seduced by numbers. However, a more basic and evidencebased reason for suggesting that the 2020 Ditchley Lecture should be interpreted as a joint endeavour is that large sections of it are clearly almost cut-and-pasted from Cumming's eclectic blog posts and particularly from his 133,000 word magnum opus 'Some thoughts on education and political priorities' (https://static.guim.co.uk/ ni/1381).

In this context the central aim of this article is to accept the sentiment expressed in the final sentence of the lecture that the authors are 'happy to be judged' and to subject their thoughts and arguments to a critical analysis which, in itself, reveals the existence of what can only be termed as 'splintered logic'. The central argument emerging from this analysis is that if 'the privilege of public service', as perceived by Gove and Cummings, offers a glimpse into the inner mind of government thinking then it is one that appears wedded to a rather unattractive model of hybrid populist technocracy that is devoid of emotional content or political understanding. It deifies a rather pure model of brutal governing efficiency that is more nightmare than vision. This is clearly a strong argument to make but the power of the ideas promoted in this lecture demand a strong response, if anything to provoke a wider conversation about the role of the state and the future of the public sphere. In order to undertake and offer this analysis this article takes advantage of the lecture's fragmented structure and reviews each of what are quite clearly five very different sections. 'Different' in terms of aims and ambitions, tone and texture and possibly even 
authorial leadership. We suggest that this failure to knit together a more free-flowing and coherent narrative is in itself symptomatic of the deeper unresolved tensions that this article seeks to foreground. We conclude with a brief reflection on exactly why the 2020 Ditchley Lecture matters and why politicising what is, in effect, a rather technocratic and depoliticised vision of politics so urgently needs to happen.

\section{Section 1: Framing Failure}

For a lecture on 'the privilege of public service', it is hard to imagine a more downbeat or depressing opening. Antonio Gramsci's Prison Notebooks are used to provide a rather obvious historical reference point: 'Now our age is not the 1930s. But it is an age of morbid symptoms. The model that the current generation of political leaders inherited has been crumbling'. If the aim of the opening of a lecture is to set the context and to prepare the ground for later arguments, then this is a framing based around failure out of which three key insights can be gleaned. The first relates to timing and the manner in which the emergence of institutional and systemic failure is conveniently tied to the dying days of the New Labour project. The period since 1945 was, we are led to be believe, a time of sunlit uplands in which the party system was stable, leaders strong, a meritocracy reigned, structures were efficient, dogs did not chase cats, and the economy blossomed ... '[B]ut since the financial crisis of 2008 those foundations and assumptions have been systematically eroded'. Just as sex began in 1963 ('Between the end of the 'Chatterley' ban/And the Beatles' first LP') as Philip Larkin proposed, so did failure apparently set in during the Annus Mirabilis that was 2008. Notwithstanding the impact of the global financial crisis it seems as dubious as it does fortuitous to select a date that so usefully chimes with the fact that, as Anthony Seldon and Stuart Ball have documented, the twentieth century was largely 'a Conservative century' (Seldon and Ball 1994). Concerns regarding the 'Crisis of Democracy', for example, a concern that Gove and Cummings explore in this opening section, formed the focus of the Trilateral Commission's major international enquiry and report of 1975 but are conveniently forgotten. Failure began in 2008 and not a moment earlier.

The second insight is that failure is interpreted very much as a product of globalisation. Economic growth has not only slowed but levels of inequality have also increased which has created a social rump, a huge section of the public that feels 'left behind'. This has created a 'them' and an 'us': 'To colour it crudely: the former are more sensitive to the harm caused by alleged micro-aggressions; the latter are less likely to be squeamish about tougher sentences for those guilty of actual physical aggression'. Some might think it slightly crude that a Conservative government minister might try to skate so swiftly across the late twentieth century and the social and economic impacts of Thatcherism more generally. Some might think it equally crude for the Oxbridge-educated authors to seek to position themselves with the 'us' (i.e. the 'left behind' and disadvantaged) against 'them' (i.e. the establishment elites). This is a very odd form of peculiarly British populism (Flinders 2020a).

But most of all (and thirdly) this is about the failure of our political processes, political institutions and politicians. We trusted them to create prosperity, we trusted 
them to give 'us' a fair slice of the pie, we trusted them to care for the sick and the elderly_and they failed us.

And all these discontents were rising as the world faced the terrible fallout from the financial crisis ... For many, they had failed to anticipate the crisis, failed to identify or take responsibility for what had gone wrong, failed to ensure the burden of repair was fairly shared, failed to reform the institutions, especially the finance and business institutions at the heart of the crisis, and overall failed to recognise the scale of change society demanded.

This is not the measured thinking or balanced optimism of Michael Gove; it is the blunt worldview of Dominic Cummings. To read the Prime Minister's chief adviser's personal blog is to enter a nihilistic world of extreme uncertainty in which the only thing that is certain is that total disaster for humanity is imminent, or as he suggests 'it's just a matter of when'. In a blog back in March 2019, for example, that now looks somewhat prophetic Cummings argued that 'The most secure bio-labs routinely make errors that could cause a global pandemic [and] are about to re-start experiments on pathogens engineered to make them mammalian-airborne-transmissible'. And yet the point being made is that, as Collini suggests, 'Existential paranoia on a galactic scale is, it seems the new normal' for Cummings, and this extreme negativity is used to rationalise the need, not just for a highly technocratic mode of statecraft, but also for a strong leader.

\section{Section 2: Bold Leadership}

'These morbid symptoms' to continue with a failure-bound theme 'weakened our politics before the terrible global impact of the coronavirus and they have shaped how many have seen the response to that crisis [emphasis added]'. And in this simple sentence, the themes of failure and leadership are conjoined into a narrative about the future out of which three insights (again) can be usefully gleaned. The first takes us back to 'them' and 'us' and how if Covid has revealed anything it is the gap between different communities: 'The disproportionate impact of the virus on BAME communities is both heart-breaking and a reproach ... But there can be no doubt that they reflect structural inequality in our society which has to be addressed'. In what is a clear and slightly awkward shift in focus, the second element focuses on how Covid underlines the twin themes of uncertainty and technology (or, more specifically, the potential of technology to tame uncertainty). The shift in style, the loss of any rhythm or cadence to the text, suggests a very different authorial tone which is more akin in quality and content to Cummings' blogposts. The 'paranoia on a galactic scale' continues as the lecture warns that, 'As we seek to restore our fractured economies and heal our divided societies following the advent of this pandemic, we must also be aware of other, complex and unpredictable, challenges still to be overcome'. This warning provides a rhetorical gateway to a whole new world of 'big data', 'machine learning', 'artificial intelligence', 'robotics', 'automation', 'quantum computing', 'genetic sequencing', 'gene editing', 'biotechnology' and 'the networks of our interconnected world'. 
The technological transition is as swift and breath-taking as it is all-encompassing and potentially overwhelming. The schizophrenic quality of the lecture has emerged at a very early stage and it would be fascinating to know the developmental process this speech went through as it passed between Gove and Cummings at various stages. At this point, for example, it's possible to imagine Gove wincing at the early technological intrusion and asking Cummings to soften things slightly by not forgetting the forgotten people; a reminder that simply fuels failure in a sense that with a flick of his pen (electronic, cordless, voice controlled, Tech 4.0 enabled) he adds: 'The changes to the workplace the Fourth Industrial Revolution is likely to bring will see many current jobs and occupations either disappear or alter dramatically. The division between the fortunate and the forgotten could deepen perilously'. Gove looks to the skies, picks up his quill and decides to soften the tone by adding that, 'as we contemplate new technological and scientific breakthroughs we must also consider the ethical and political challenges they bring'; at which point Cummings growls into his smart-pen and adds, 'Unless they are thoughtfully addressed, we risk further worsening the morbid symptoms of our times'.

And so the 2020 Ditchley Lecture unfolds in a rather curious pattern that often feels like you are listening to two people arguing rather than anything resembling a coherent view of how to address the challenges and opportunities of governing in the twenty-first century. There is, it appears, a measured and thoughtful politician on the stage and a 'wild man in the wings' which might not be so worrying, and possibly even funny, if we were not talking about the Minister for the Cabinet Office and the Prime Minister's chief advisor.

The only area where harmony ensues lies in the shared agreement that what is really needed to avert failure, disaster, crisis and catastrophe is strong leadership. Not just any leader but one that is 'flexible, adaptive and empirical'. The third and possibly most puzzling element of this section of the lecture is the manner in which it apparently sees no contradiction at all in plucking-out Franklin Delano Roosevelt as the acme of modern leadership. Looking forward to a technologically enhanced Industrial 4.0 world by looking backwards nearly a century to a world when encyclopaedias were sold door-to-door (once again) seems slightly incongruous but apparently he is just the sort of male, white 'heroic' leader that Gove and Cummings feel is needed today. Why? Because 'FDR managed to save capitalism, restore faith in democracy, indeed extend its dominion, renovate the reputation of Government, he set his country on a course of increasing prosperity and equality of opportunity for decades - and enabled America to emerge from a decade of peril with the system, and society, that the free citizens of the rest of the world most envied'. There is no doubt that FDR was a remarkable leader but there is doubt as to whether the qualities and achievements can be plucked-out of history and almost offered as the salvation for the future. To read the state-of-the-art research on modern leadership is to understand the role of teams in which different people take on different leadership roles. Even where a single leader exists the most effective leadership styles tend to see him or her adopting a more team-based or collaborative style but certainly not up in front on a white stallion in the way the 2020 Ditchley Lecture seems to view leadership. This view of leadership is also somewhat at odds with the lecture's technological emphasis on the management of complex networks, integrating and 
better-sharing data and with forging high-trust, low-cost relationships. At odds, that is, until the end of the section and when it becomes clear that what FDR has really been brought into the equation for is less about historical relevance and leadership styles and more about the simple fact that 'he recognised that faced with a crisis that had shaken faith in Government, it was not simply a change of personnel and rhetoric that was required but a change in structure, ambition and organisation [emphasis added]'.

\section{Section 3: Deep Reform}

'This Government in the UK was elected on the basis that it would be different from its predecessors ... and events have only made that mission of change more urgent' Gove (and Cummings) state. 'But if this Government is to reform so much, it must also reform itself. As FDR recognised, the structures, ambitions and priorities of the Government machine need to change if real reform is to be implemented and to endure'. And with this the lecture has, at last, got to its core concern and a focus on the need not just for old-fashioned, traditional 'reform' but for 'transformative reform', and (once again) this is a section of two distinct halves that seems to be written by two different people. It begins with a strange nod towards the actual title of the lecture and a slightly sickly pronouncement that 'Public service is a privilege. Not because it brings wealth or ease ... No, the privilege comes from knowing that those of us in Government have the chance every day to make a difference'. In a distinct shift in rhetorical style that appears (but fails) to draw inspiration not from FDR but from Teddy Roosevelt's 'The Man in the Arena Speech', the lecture rather loftily states, 'The greatest gift that any of us can be given is the opportunity to lead lives of purpose in public service - to know that by our efforts others stand taller'. There is something rather dated and irksome by such pronouncements; too much of the 'shoulders back, chests out, stiff-upper lip' public school playing fields and too little of the gritty realities of public service as experienced by the teachers, police officers and social workers of Swindon, Sheffield and Scunthorpe.

It's possible that a brave proof-reader, possibly even one of the 'weirdos and misfits' that Cummings has been keen to recruit into the centre of Whitehall, made exactly this point as the very next paragraph mentions Mansfield, Middlesborough and Merthyr Tydfil and the need not to overlook 'hitherto undervalued communities'. But such territorial targeting feels slightly false and forced; like the use of FDR, little more than a tool through which to present a position and three points that have already been decided and which revolve around the themes of bubbles, range and delivery.

Anyone who has read Dominic Cummings' writing about what he terms the 'dysfunctions of Whitehall' will have come across his focus on 'the hollow men in the bubble' which is essentially his shorthand term for how he views a large proportion of the civil service (Cummings 2014). The notion of 'hollow men' invokes T. S. Elliot's 1925 poem of the same name ('We are the hollow men/We are the stuffed men/Leaning together/Headpiece filled with straw'/Alas! Our dried voices, when/ We whisper together/Are quiet and meaningless/As wind in dry grass/Or rats' feet 
over broken glass/In our dry cellar/Shape without form/shade without colour/Paralysed force/gesture without motion'). To be described as a member of the 'hollow men' is from Cummings' position more critical than it is poetical and chimes with the conviction that too many civil servants enjoy the privileges of public service but possibly not the responsibilities that should go with it (discussed below). Although the notion of 'the bubble' or joining a 'bubble' has developed a very specific riskrelated relevance in recent months, Dominic Cummings' discussions of 'the bubble' go back many years and focus on what might be termed an administrative malady rather than an epidemiological concern. For him too many civil servants exist within a small and somewhat incestuous Whitehall and Westminster 'bubble' which, when combined with the incentives created by the current institutional structures, simply encourages a form of 'groupthink' in which basic assumptions are never challenged, mistakes never admitted, responsibilities never accepted or problems ever actually addressed. As Cummings has written in one of his blogs,

Most of our politics is still conducted with the morality and the language of the simple primitive hunter-gatherer tribe ... Our 'chimp politics' has an evolutionary logic: our powerful evolved instinct to conform to a group view is a flip-side of our evolved in-group solidarity and hostility to out-groups ... This partly explains the persistent popularity of collectivist policies ... and why 'groupthink' is a recurring disaster.

The reason for pointing out this Cummings worldview is that it forms the clear focus of the third part of the 2020 Ditchley Lecture. This is pure Cummings and even the rather odd attempt to veil this fact by referring not to 'the bubble' but to the existence of 'a looking glass world' in which, 'Government departments recruit in their own image, are influenced by the think tanks and lobbyists who breathe the same London air and are socially rooted in assumptions which are inescapably metropolitan' does very little to disguise this fact. The problem with 'the bubble' is that it is rarely pricked or popped in the sense that its members are forced to question their world view, take responsibility for failure or-quite simply-deliver. And here we have a glimpse at the true essence of the depoliticised technocratic approach to governing that will later become the hallmark of the lecture. It's not the 'radical initiatives' or 'dramatic overhauls' - 'ramping-up this and rolling-out that' — which matter but 'the boringly transformative' (i.e. the simple act of predicting challenges and delivering solutions, nothing more, nothing less). Which brings us to the issue of range. The problem with government, it is suggested, is that its upper echelons are far too 'reliant on those with social science qualifications' and under-equipped when it comes to science, technology and mathematical skills. This is hardly a new issue to raise and it may well be the case that what Gove and Cummings refer to as 'the talent pool' needs to draw upon the insights of a wider range of scientific disciplines. And yet there is arguably a deeper critique of the social sciences that lurks within this lecture. That is a critique that obliquely appears to blame the social sciences for being somehow inauthentic-it's members representing a sub-section of the middle-class, cosmopolitan, 'anywheres' who are to some extent insulated from the impacts of globalisation and who failed to predict or understand why $52 \%$ voted Leave. Cummings is typically blunt: 'The study of management, like politics, is not 
a field with genuine expertise', he blogged in March 2019 '[L]ike other social sciences there is widespread 'cargo cult science', fads and charlatans drowning out core lessons' (Cummings 2019). And the 'core lesson' is set out as follows:

'In the 2016 referendum those who had been too often forgotten asked to be remembered', Gove and Cummings note as part of a broader argument about the need to ask 'how can we be less anywhere and more somewhere'? David Goodhart's 2017 book, 'The Road to Somewhere' is therefore presented as the literary touchstone of the embryonic project but what this lacks is an understanding of the importance of range (to use the title of David Epstein's 2019 book on the topic.

Put very simply, what Epstein demonstrates through a detailed review of the available evidence is that what we don't need in terms of thinking about future challenges and potential responses is more of one thing and less of another, but a more integrated and positive-sum approach that understands the need to nurture the knowledge base with a range of perspectives. Range in this sense simply denotes intellectual vibrancy and criticality, which would seem to dovetail almost perfectly with Cummings' writing on the need for diversity and challenge but does not tally with a rather odd side-swipe at the social sciences. What the social sciences bring to the policy-making process, as the Coronavirus challenge has underlined, is an understanding of individual and social behaviour without which the full potential of scientific and technological breakthroughs are unlikely to be fully realised. And yet the full realisation of some notion of technologically driven future-focused 'full potential' is, at its core, what the 2020 Ditchley Lecture is really about. When all is said and done about leadership and the 'left behind', and about bubbles and breaking the looking glass, what everything in the lecture actually comes down to is, '[D] elivery on the ground; making a difference in the community; practicable, measurable improvements in the lives of others should matter more ... At the heart of our programme must be a focus on what works-what actually helps our fellow citizens to flourish'.

\section{Section 4: 'What Works' or 'Cummings Unleashed'}

This lecture has already been characterised as possessing a certain Jekyll and Hyde quality due to the manner in which it so clearly swings and sways-or, more precisely, zigs and zags-from balanced insightful analysis towards broad sweeping generalisations. It's a lecture with segments and sections clearly written by two very different authors, and although there is a clear connection in terms of the canvas on which they are attempting to paint there is also a strong disconnect in terms of styles, colour and contrast. One author paints with gentle brush strokes using subtle shades of colour, while the other paints with slash-strokes using only primal tones. The former almost appearing to be holding the latter back; the lecturer on stage with 'the mad man in the wings'. It is, however, in the fourth and most substantive section of the lecture that the influence of Dominic Cummings is arguably most obvious and to some extent concerning. The 'mad man'-a term used in a purely Chomskian sense to identify an intellectual, outsider or maverick who wishes to unleash their disruptive spirit-takes centre stage with a laser-like focus on the need to adopt 
what can only be described as a data-driven model of technocratic governance. We are not suggesting for one minute that Michael Gove does not support this agenda but are simply making the point that in this part of the lecture there are clear and direct links across to the more strident arguments that have previously been made in the writing of Dominic Cummings. What's interesting about Cummings' position, to return to Chomsky's work on the responsibility of intellectuals, is that it is as valueladen and arguably emotional as it is technocratic and policy-focused. It is a hybrid of traditional intellectual styles and this may help explain not only the divergences and disconnections noted in this lecture but also the broader confusion, bordering on mysticism, surrounding Dominic Cummings.

Continuing with a by now familiar pattern we suggest that three inter-related insights - scientisation, specialisation and simplicity-can be extracted from this section and used as the basis of a discussion about the evolution of government policy, in general, and the mind of Dominic Cummings, more specifically.

The Cummings agenda for British government, if the 2020 Ditchley Lecture is taken as some form of political smoke-signalling or exercise in intellectual refinement, can be summed-up in one word-'scientisation'. This is a clumsy word and possibly even a neologism but what it points to is the application of a very clear ontological, epistemological and methodological framework onto the business of government. Its raison d'être is simply the discovery and application of 'what works'. Period. What we need to transform public service are less 'sugar rush' headline policy announcements and more of a simple focus on generating 'hard, testable, data' about whether any given policy has 'worked'. This is the 'boringly transformative' and to enter the Elysium of Cummings' inspired statecraft is therefore to enter the world of integrated performance management in which the central question is not 'how much money are we spending on X. Y or Z?' but 'how we can demonstrate the value of that investment?' And yet this approach goes far beyond the well-known precepts and tools of New Public Management and embraces the tools of 'real' science to ask the tough questions that politicians and their officials have so far managed to duck. 'What are the metrics against which improvement will be judged? How are appropriate tools such as randomised controlled trials being deployed to assess the difference being made? How do we guard against gaming and confirmation bias? All across Government at the moment that widespread rigour is missing'.

Not only is the necessary 'rigour' apparently 'missing' but the government also needs to be 'fearless' in injecting the rigour that is apparently missing. Indeed, 'Government needs to be rigorous and fearless in its evaluation of policy and projects' [emphasis added]. Rigorous, fearless and forgetful the critical listener might suggest: 'Wasn't a focus on 'what works?' a key element of New Labour's approach?' As Michael Barber's 2007 book Instruction to Deliver: Tony Blair, the Public Services and the Challenge of Achieving Targets underlines, the creation of the Prime Minister's Delivery Unit was forged upon a focus on 'What Works'. The fact that such obvious historical facts are simply ignored is somewhat worrying and yet the reason for the omission is arguably to be found (once again) on Cummings' website and in a review he published on 7 July 2015 on Michael Barber's 2015 book How to Run a Government (Cummings et al. 2015). The problem with previous attempts, Cummings suggests, to focus on efficient service delivery is that they achieved results 
generally by 'picking very low-hanging fruit'. Barber ('a nice man who believes the best of politicians') and his team of consultants are 'providing what should be minimal competence for people who do not know how to prioritise and are managerially incompetent'. Although Cummings views Barber's emphasis on 'deliverology' as 'better than government by spin and gimmick, [it] is only a recipe for forcing a few priorities through routinely incompetent bureaucracies', whereas Cummings ambition is to achieve deeper transformational change, even to the extent of exploring new 'man-robot collaborations'.

Data and technology are, as might be expected, the twin pillars of this (latest) revolution in government which, in turn, creates a need to recruit a new technological elite. At this point the lecture takes on a rather bizarre tone as Michael Gove quietly concedes that ' $[\mathrm{T}]$ here are many brilliant people in our civil service', before, in what reads like a Cummings-like interjection, adding that there aren't many officials with qualifications in 'mathematical, statistical and probability' and that what we need (because mathematical reasoning is the future) is to ensure that 'more policy makers and decision makers feel comfortable discussing the Monte Carlo method or Bayesian statistics'. (As all readers will undoubtedly already know the Monte Carlo method, or more precisely experiments, are a broad class of computational algorithms that rely on repeated random sampling to obtain numerical results, the underlying concept is to use randomness to solve problems that might be deterministic in principle). This is the scientisation of politics; the belief in a pure, structured, depoliticised, technocratic and highly mechanical view of decision-making which reads, in line with the splintered style of the lecture, somewhere between an old academic textbook and a rejected script line from Yes, Minister.

Moreover, what is promoted as a transformative approach to governing is an approach that also sees the inevitably messy and emotionally charged business of politics as a clear and linear process. Emotions are irrational human qualities best set aside in favour of efficiency. Indeed, what ministers need are not wide-ranging analyses of complex social challenges but 'tight, evidence-rich, fact-based, argument which doesn't waste words or evade hard choices'. What politicians and the public therefore really need are experts: 'As in deep, domain-specific, knowledge'.

The privilege of public service is therefore tied to an emphasis on both science and specialisation and the problem with government is that its senior officials spend too much time learning about "vapid abstractions such as "Collaborating Better" rather than-to use one of the examples given-learning about 'how to interrogate climate modelling'. The interesting element of this section of the lecture is that it raises a number of issues and challenges that very few people, irrespective of their political hue, would disagree needed addressing. The downside, however, is that these issues and challenges have been identified and discussed for years, if not decades. The lecture highlights the rotational dynamics embedded in civil service careers, for example, and the impact this has on individual efficiency and broader institutional memory. This is a hoary old chestnut but hardly a transformational insight. (It did, however, facilitate the use of the word 'whirligig' which is so obviously a Gove'arian insertion that it may have been his main contribution to this section.) In what can only be interpreted as a Cummings'arian assertion that goes completely against the existing science base, we are told that 'mastery of deep 
knowledge is the precondition of creativity and open-mindedness'. When drafting their next lecture Messrs Gove and Cummings would be well advised to reflect upon the insights contained within Albert Rothenberg's 2015 book, Flight from Wonder: An Investigation of Scientific Creativity and particularly the 'tight, evidence-rich, fact-based' argument it presents about deep granular knowledge being of little benefit without being matched by a sense of breadth and perspective.

This in itself might highlight the manner in which the brand of what has been labelled 'scientisation' promoted in this lecture appears to be underpinned by a bizarre blend of elitism and populism in which the problem with politics is that it allows too many imbeciles and incompetents to wield power instead of just letting the experts get on with governing. Great sections of the lecture read like slightly sanitised versions of previously published articles by Cummings in which he laments the manner in which 'the daily routines of Westminster ... operate against having serious people in charge of things-people who know how to set priorities, focus and manage complex processes ... Why do we have to be governed by Cleggs while our finest minds, entrepreneurs, and so on are shut out of government?'(Cummings 2014)

And if anything this point alerts us to what is missing about the 2020 Ditchley Lecture: a sense of breadth and perspective. The emphasis on science, specialisation and 'serious people' is just too clean and simple. Whether by definition, design or default the argument offered seems unable to accept that there are no simple (social) solutions to complex (political) problems waiting to be discovered if we could only get the right experts in front of the right computer crunching the right data at the right time. The logic promoted in the lecture is not only splintered in authorial terms but also somewhat splintered from reality in the sense that the political landscape is in fact an emotional landscape. Indeed, possibly the most striking element of this lecture, especially given its rhetorical emphasis on reconnecting with the 'left behind', is its almost complete lack of empathy, of feelings, or emotion. It offers a cold and mechanical and potentially dangerous agenda for the future of politics which might explain why the final section suddenly adopts a very different and softer tone.

\section{Section 5: 'A Personal Note' or 'Gove Returns'}

As we have already suggested, the fourth section of the 2020 Ditchley Lecture adopted what in Whitehall parlance might be described as 'a very brave approach'. It presented a rather extreme version of technological populism in which what matters is 'what counts' and where data-driven specialists utilising the very latest insights in algorithmic governance will be able to ensure that democratic politics (if this still counts as democratic politics) will be able to 'make all sad hearts glad' (For an interesting discussion see Gritsenko and Wood 2020). In doing so, it will refute the honesty that Bernard Crick sought to promote in his classic book, In Defence of Politics (first published in the year that the Ditchley lectures began) when he admitted that politics 'cannot make all sad hearts glad'. The risk of privileging a technocracy in the manner adopted in this lecture is that it risks lifting the public's expectations 
to the point that failure is to some extent arguably inevitable. What the model of transformational statecraft suggested in this lecture seems unable or unwilling to acknowledge is that 'feelings generally trump facts' in the sense that it doesn't really matter if politicians are data-rich, or their officials highly specialised; what matters is what and how people feel and the capacity for politicians and their officials to understand why emotions matter and why they cannot be so easily dismissed by an emphasis on the facts of the matter at hand (Flinders 2020b). Try talking Monte Carlo Methods and Bayesian statistics to the good people of Delabole, Doncaster or Darlington.

This might explain the rather odd reorientation of the lecture that marks its fifth and final section. It's as if the author of the fourth section is suddenly deposed in favour of a far warmer and measured set of tones. 'The heart of my case', Gove tells the audience as he returns from the wings to regain control of the narrative, 'as I hope everyone now appreciates, is simple'. 'Simple', however, not in the purely mechanical and data-driven sense but simple at a more emotional level to the extent that we are told that Mr Gove wakes up every morning 'saddened by the fact we [the government] haven't done more to make the most of every talent in our land, reproaching myself that we did not do more in children's social care, primary schooling and secondary schooling to provide opportunities and keep young people safe'. In a crescendo of emotion, the Minister for the Cabinet Office admits his own emotional frailties with the admission that 'I worry that we have not succeeded in reforming the youth justice system, the police, the CPS and the courts', but pulls things round with an Obama-like declaration that 'we can do better, we can redeem souls, we can save lives through public sector reform'. Such soaring rhetoric is, however, brought crashing down to the procrustean realities of the technocratic vision previously outlined when a voice from the wings adds, if only money was 'properly authorised and its spending effectively evaluated then massive progress can be made'. If only it really was that simple. Which brings us to offer three concluding insights — on the topic of experts, the mechanics of change and the government's approach to power-in order to cultivate the broader conversation that the 2020 Ditchley Lecture was undoubtedly designed to stimulate.

The first point is as obvious as it is simple: the starkest paradox of Gove's approach to 'the privilege of public service' is that his agenda, according to this lecture, relies upon the privileging, above all else, of expertise. If anything it is this shared belief in the potential power of expertise that forms the bridge or buckle between the two very different worldviews of Michael Gove and Dominic Cummings, but while the latter has little to lose from an affiliation with 'the experts', the former is arguably skating on thin ice. Can this really be the man that argued during the lead up to the EU that 'the people in this country have had enough of experts'? Gove's strategically selective approach to expertise risks torpedoing Cummings emphasis on rationality from the outset. The second issue relates to the tools of change or, more specifically, to the role and responsibilities of the two organisations that are mentioned in the final throes of the lecture-GovernUp and the Commission for Smart Government.

GovernUp is, according to its website, an independent, non-party research initiative which has been active since 2014, offering evidenced-based solutions for all 
political parties to adopt and working to produce a rigorous body of evidence to identify the strengths and weaknesses of the current system of government, generate radical but workable solutions to the long-term challenges that require reforms, and shape public debate and build a new cross-party consensus on reform. GovernUp is therefore a think tank. While not quite as Orwellian in tone as much of this lecture, it adopts a data-driven, evidence-based and largely depoliticised approach to social challenges and will at some point in the future be announcing the launch of a 'Commission for Smart Government'. Have you noticed that everything today has to be 'smart'? Smart-televisions, smart central heating systems, even smart-toothbrushes and smart supermarket trolleys that utilise real-time data and the latest technology to 'empower' their users. And herein lies the rub. GovernUp is a pretty poor organisational affiliation for a political lecture based upon the need to GovernDown through localism and not forgetting those who feel forgotten. And yet even this misalignment points to the existence of a far broader tension in the sense that the mode of populist technocratic statecraft embodied within this lecture sits itself within a broader constitutional configuration that is already facilitating an extreme centralisation of executive power. From the prorogation of Parliament through to expelling members of the Party, through to interfering in the election of Select Committee chairs through to refusing (until lately) to appear before the Liaison Committee. (Not to mention bungled bids to nobble the Intelligence and Security Committee.) The balance of power between the legislature and the executive, for decades a source of deep concern, has clearly and significantly swung from the former to the latter. Add to this the manifesto promise of a 'Constitution, Democracy and Rights Commission' and the drift towards a very different model of British democracy looks clear. Safeguarding the constitution in stressful times, as Andrew Blick and Peter Hennessy have recently argued, is difficult in a system that depends upon self-restraint. This is a critical point. The 2020 Ditchley Lecture and the simplistic, technocratic and centralising logic that exist within it does not exist in isolation but forms a key strand of a far broader and potentially dangerous view of governing that is taking shape. Facts must be collected, technology enhanced, and dissent quashed. Loyalty to the cause of efficiency is what matters but if it is the ideological foundations offered in this lecture that underpins this strategy, then we are all in trouble. The defence and promotion of the privilege of public service can never be based on such ultimately and obviously splintered logic. It is just so hollow, hollow, hollow ...

\section{References}

A full list of previous Ditchley Lectures and transcripts can be found. https://www.ditchley.com/progr amme/annual-lecture

Chomsky, N. 1967. The responsibility of intellectuals. In The New York review of books. https://choms ky.info/19670223/. Accessed 10 July 2020.

Collini S. 2020. Inside the mind of Dominic Cummings. The Guardian. https://www.theguardian.com/ politics/2020/feb/06/inside-the-mind-of-dominic-cummings-brexit-boris-johnson-conservatives. Accessed 10 July 2020.

Cummings, D. 2014a. Babble in the bubble: UFSM, Clegg's lies and the general dysfunction of the British state. https://dominiccummings.com/2014/05/13/babble-in-the-bubble-ufsm-clegg-and-thegeneral-dysfunction-of-the-british-state/. Accessed 10 July 2020. 
Cummings, D. 2014b. Gesture without motion from the hollow men in the bubble, and a free simple idea to improve things a lot which could be implemented in one day (Part I). https://dominiccummings .com/2014/06/16/gesture-without-motion-from-the-hollow-men-in-the-bubble-and-a-free-simpl e-idea-to-improve-things-a-lot-which-could-be-implemented-in-one-day-part-i/. Accessed 10 July 2020.

Cummings, D. 2015. Book review - 'How to run a Government' by Michael Barber. https://dominiccum mings.com/2015/07/07/book-review-how-to-run-a-government-by-michael-barber/. Accessed 10 July 2020.

Cummings, D. 2019. On the referendum \#31: Project Maven, procurement, lollapalooza results \& nuclear/AGI safety'. https://dominiccummings.com/2019/03/01/on-the-referendum-31-projectmaven-procurement-lollapalooza-results-nuclear-agi-safety/. Accessed 10 July 2020.

Epstein, D. 2019. Range: How generalists triumph in a specialized world. London: Penguin.

Flinders, M. 2020a. Not a Brexit Election: Pessimism, Promises and Populism 'UK-style'. Parliamentary Affairs 73 (4): 225-243.

Flinders, M. 2020b. Why feelings trump facts: Anti-politics, citizenship and emotion. Emotions and Society 2 (1): 21-40.

Gritsenko, D., and Wood, M. 2020. Algorithmic Governance: A Modes of Governance Approach. Regulation \& Governance.

Seldon, A., and S. Ball. 1994. Conservative century: The conservative party since 1990. Oxford: Oxford University Press.

Publisher's Note Springer Nature remains neutral with regard to jurisdictional claims in published maps and institutional affiliations. 